BEduManageRs Journal

Borneo Educational Management and Research Journal, Vol.1, No.1, 2020

ISSN: 2747-0504

\title{
Implentasi Kebijakan Penerimaan Peserta Didik Baru Dinas Pendidikan Dan Kebudayaan Kota Samarinda
}

\author{
Sukarni $^{1}$, Nur fitriyah ${ }^{2}$, Sestuningsih $^{3}$ \\ Universitas Mulawarman \\ e-mail:doktormp@fkip.unmul.ac.id
}

\begin{abstract}
One of the very important aspect in the Education is related to the enrollment of new students which has a very complex problems. To overcome all the problems, the District Head Office of the Education and Culture Kota Samarinda, published a policy on the new students enrollment, year 2016/2017 by using online system/model. This research Purposes are (1) to describe the implementation of the District Head Office of the Education and Culture Kota Samarinda for new students enrollment policy, year 2016/2017 for SMA level and (2) to know how the implementation of the District Head Office of the Education and Culture Kota Samarinda for new students enrollment policy, year 2016/2017 can be accepted by community. This research uses qualitative approach with the technique of data collection through indept interview, observation and the documentation study. The sources of the informations for this research are the school headmasters and new student parents/new students. The research findings are (1) according to the school headmasters (the policy implementors), year 2016/2017 that the new students enrollment policy can be implemented on the SMA levels, although there are some problems associated with the students non-academic achievements, disability/Environment Devolopment(ED)/PTK, and the school capacity and the stages of the registration path. While according to the new students' parents/ new students, the new students enrollment policy, year 2016/2017 can be accepted with four notes, namely the problem of the non-academic students' achievement, disability/ED/PTK, school capacity and the stages of the new students enrollment path; (2) related to the registration phase students' non-academic achievements, disability /ED/PTK done before the regular /general path, causes many problems; (3) system/model of selection for students' non-academic achievements, disability/ED/PTK based on the leves of the highest value of the National Examination results causes problems; and (4) the school capacity according to the policy implementors and new students' parents/new students hope the government provides enought school capacity for the community; and (5) Headmasters always have their HP on and they are always at school.
\end{abstract}

KeyWords: the implementation policy, new students enrollment, implementor policy, target group.

\section{PENDAHULUAN}

Dalam rangka memberikan pelayanan pendidikaan kepada masyarakat dengan baik secara adil dan merata sesuai dengan Undang-Undang Sistem Pendidikan Nasional (Sisdiknas) nomor 20 Tahun 2003, pasal 4 (1) dan (6) perlu kebijakan yang mengatur penyelenggaraan pendidikan yang bermutu. Salah satu aspek yang sangat penting adalah berkaitan dengan penerimaan peserta didik baru (PPDB). Agar penyelenggaraan PPDB berjalan tertib, lancar, transparan, akuntabel, dan adil, maka diatur secara khusus melalui Peraturan Bersama antara Menteri Pendidikan Nasional dan Menteri Agama Nomor 2/VII/PB/2014 Nomor 7 Tahun 2014 Tentang Penerimaan Peserta Didik Baru tahun pelajaran 2015/2016, pasal 6 (1) 
BEduManageRs Journal

Borneo Educational Management and Research Journal, Vol.1, No.1, 2020

ISSN: 2747-0504

Persyaratan calon peserta didik baru kelas 10 (sepuluh) SMA dan Madrasah pada tanggal 1 Juli tahun berjalan 2015/2016 adalah :

a. telah lulus dan memiliki ijazah/STTB SMP/SMPLB/MTs/Paket B/Pendidikan Pesantren Salafiyah Wustha/sederajat;

b. memiliki SKHUN SMP/SMPLB/MTs/Paket B/Pendidikan Pesantren Salafiyah Wustha/sederajat; dan c. berusia paling tinggi 21 (dua puluh satu) tahun pada awal tahun pelajaran baru.

Jumlah peserta didik pada SMA dalam satu rombongan belajar/kelas paling banyak 40 (empat puluh) orang. Dalam pasal 11 ayat:

(1) Seleksi calon peserta didik baru kelas 10 (sepuluh) SMA dan Madrasah dilakukan berdasarkan:

a. SKHUN SMP/SMPLB/MTs/Paket B/Pendidikan Pesantren

Salafiyah Wustha/sederajat;

b. Jarak tempat tinggal ke sekolah;

c. usia calon peserta didik baru;

d. prestasi di bidang akademik;

e. bakat olah raga atau bakat seni; dan

f. prestasi lain yang diakui sekolah.

(2) Apabila kriteria sebagaimana dimaksud pada ayat (1) tidak terpenuhi, sekolah dapat melakukan tes bakat skolastik atau tes potensi akademik.

(3) Seleksi calon peserta didik baru kelas 10 (sepuluh) SMA dan Madrasah wajib menerima paling sedikit $20 \%$ (dua puluh persen) bagi calon peserta didik yang berasal dari keluarga ekonomi kurang mampu.

Kebijakan tersebut, secara jelas dan rinci telah mengatur pelaksanaan PPDB berdasarkan azas yang berkeadilan, transparan dan akuntabel. Kebijakan tersebut diharapkan dapat memberikan akses pelayanan masyarakat dengan baik dan bermutu secara adil dan merata sesuai dengan kemampuan daya tampung sekolah.

Dalam rangka melaksanakan amanat UU, Peraturan Pemerintah, Peraturan Daerah, maka Dinas Pendidikan dan Kebudayaan Kota Samarinda membuat kebijakan yang dituangkan dalam Petunjuk Teknis (Juknis) tentang pelaksanaan PPDB tahun pelajaran 2015/2016 secara lebih rinci. Juknis tersebut sebagai pedoman bagi sekolah-sekolah dalam pelaksanaan PPDB tahun pelajaran 2015/2016. Tujuan pembuatan petunjuk teknis adalah :

a. Meningkatkan Angka Partisipasi Kasar (APK) dan Angka Partisipasi Murni (APM) Kota Samarinda pada taraf paripurna;

b. Memberikan pelayanan pendidikan secara merata, adil dan berkualitas kepada semua warga di Kota Samarinda;

c. Meningkatkan mutu pendidikan di Kota Samarinda;

d. Meningkatkan daya saing yang sehat antar sekolah di Kota Samarinda;

e. Mengukur seberapa jauh kualitas anak didik untuk menghadapi jenjang pendidikan yang lebih tinggi.

Adapun target yang ingin dicapai untuk jenjang SMA adalah lulusan SMP/MTs atau yang sederajat sekitar 12.787 orang dapat tertampung pada jenjang pendidikan tersebut. Upaya Dinas Pendidikan dan Kebudayaan Kota Samarinda mengurangi bahkan menghilangan permasalahan yang selalu muncul dalam pelaksanaan PPDB, melalui penyusunan pedoman PPDB yang dilakukan dengan langkah-langkah sebagai berikut :

a. Menampung usulan daya tampung dari sekolah;

b. Menganalisis dan menetapkan daya tampung setiap sekolah;

c. Melakukan sosialisasi pedoman PPDB kepada seluruh Kepala Sekolah dan Pengawas serta stakeholder pendidikan.

Pedoman Pelaksanaan penerimaan PPDB tahun pelajaran 2015/2016 mengatur jalur penerimaan, seperti Jalur reguler/umum, jalur khusus (jalur prestasi, jalur kerja sama luar negeri dan dunia industri, dan Jalur sekolah alternatif), persiapan, persyaratan, daya tampung, seleksi, jadwal kegiatan, pembiayaaan dan penggunaan dana, mutasi peserta didik, dan peraturan tambahan.

Penerimaan PPDB jenjang pendidikan Sekolah Menengah Atas (SMA) menggunakan persyaratan sebagai berikut : 
BEduManageRs Journal

Borneo Educational Management and Research Journal, Vol.1, No.1, 2020

ISSN: 2747-0504

a. Memiliki STL (surat Tanda Lulus) SMP/MTs, ijazah program Paket B atau Surat Keterangan Yang Berpenghargaan Sama (SKYBS) dengan STTB SMP/MTs;

b. Mempunyai SHUN (Sertifikat Hasil Ujian Nasional) SMP/MTs, atau Daftar Nilai Pehabnas (DNP) Program Paket B atau Daftar Ujian Persamaan Tamat SMP/MTs;

c. Berusia setinggi-tingginya 21 tahun pada awal tahun pelajaran 2015/2016;

d. Lulus seleksi administrasi PPDB;

e. Bagi calon yang diterima diwajibkan mengikuti tes narkoba.

Daya tampung untuk jenjang pendidikan SMA maksimal 36 siswa dalam satu kelas dan sistem seleksinya adalah seleksi administrasi, yaitu sesuai dengan persyaratan yang diberlakukan dan seleksi jumlah nilai tertinggi UN SMP/MTs.

Namun demikian, kebijakan-kebijakan yang diharapkan dapat menyelesaikan masalah PPDB, ternyata belum mampu menghilangkan permasalahan yang muncul dalam PPDB.

Aspek PPDB merupakan salah satu aspek dalam penyelenggaraan pendidikan di sekolah mempunyai permasalahan yang sangat kompleks. Permasalahan tersebut berkaitan dengan masalah administrasi, teknis pelaksanaan, daya tampung, calon peserta didik, orang tua calon peserta didik atau masyarakat yang menginginkan anak-anak mereka dapat diterima di sekolah yang mereka inginkan, masalah kepanitiaan, manajemen birokrasi, lembaga atau instansi terkait serta perilaku masyarakat dan birokrat yang tidak transparan dan lain sebagainya.

Kebijakan penerimaan peserta didik baru (PPDB) tahun pelajaran 2016/2017 dibuat bertujuan antara lain :

1. Meningkatkan mutu dan pelayanan pendidikan,

2. Pemerataan dan perluasan akses pendidikan, dan

3. Mengatur prosedur operasional pendaftaran, seleksi, dan pengumuman penerimaan peserta didik baru pada sekolah.

Adapun tujuan penelitian ini adalah :
1. Mengetahui kebijakan PPDB dengan sistem/model online pada jenjang pendidikan SMA,

2. Mengetahui implementasi kebijakan PPDB tahun pembelajaran 2016/2017 yang berkaitan dengan jalur prestasi, disabilitas/Bina Lingkungan/PTK,

3. Mengetahui implementasi kebijakan PPDB tahun pelajaran 2016/2017 yang berkaitan dengan tahapan jalur penerimaan, dan

4. Mengetahui daya tampung jenjang pendidikan SMA dalam penerimaan PPDB tahun pelajaran 2016/2017.

\section{KAJIAN TEORI}

1. Kebijakan Publik

Dunn, (2003 : 132) menyebutkan istilah "Kebijakan publik merupakan pola saling bergantung yang kompleks dari pilihan-pilihan kelompok yang saling mempengaruhi, termasuk keputusankeputusan untuk tidak bertindak, yang dibuat oleh badan atau kantor pemerintah".

Kebijakan publik dilihat dari perspektif instrumental, adalah alat untuk mencapai suatu tujuan yang berkaitan dengan upaya pemerintah mewujudkan nilai-nilai kepublikan. Nilai-nilai kepublikan sebagai tujuan kebijakan tersebut dapat memiliki wujud bermacam-macam. Namun demikian secara umum kebijakan publik adalah alat untuk (1) mewujudkan nilai-nilai yang diidealkan masyarakat seperti keadilan, persamaan, dan keterbukaan; (2) memecahkan masalah yang dihadapi oleh masyarakat, seperti masalah kemiskinan, pengangguran, kriminalitas, dan pelayanan publik yang buruk; (3) memanfaatkan peluang baru bagi kehidupan yang lebih baik bagi masyarakat seperti mendorong investasi, inovasi pelayanan, dan peningkatan ekspor; dan (4) melindungi masyarakat dari praktik swasta yang merugikan misalnya pembuatan undang-undang perlindungan konsumen, ijin trayek, dan ijin gangguan (Purwanto EA dan Sulistyastuti DR, 2012 : 64).

Menurut Dye dalam Suntoro Irawan dan Hariri Hasan (2015 : 3) kebijakan publik adalah " is whatever government chooses to $d o$ or not to do". Artinya, kebijakan publik adalah apapun yang dipilih oleh pemerintah 
BEduManageRs Journal

Borneo Educational Management and Research Journal, Vol.1, No.1, 2020

ISSN: 2747-0504

untuk dilakukaan atau tidak dilakukan. Sedangkan menurut Easton dalam Suntoro Irawan dan Hariri Hasan (2015 : 3) kebijakan publik adalah "the authoritative allocation of value for the whole society but it turns out that only the government can authoritatevely act on the whole society, and everithing the government chooses to do or not to do results in the allocation of values".

Grindle dalam Haedar, Akib; Antonius Tarigan dalam Mulyadi Deddy (2015 : 47) mengemukakan bahwa implementasi merupakan proses umum tindakan administratif yang dapat diteliti pada tingkat program tertentu. Sedangkan Van meter dan Van Horn dalam Wibawa, dkk dalam Mulyadi Deddy (2015 : 47) menyatakan bahwa implementasi kebijakan merupakan tindakan yang dilakukan oleh pemerintah dan swasta baik secara individu maupun kelompok yang dimaksudkan untuk mencapai tujuan.

Implementasi merupakan suatu proses dan proses implementasi kebijakan publik sangat dipengaruhi oleh tujuan yang ingin dicapai. Adapun tujuan kebijakan harus dirumuskan secara akurat sebelum kebijakan dilaksanakan. Gerston dalam Muhdi dan Sapto Budoyo, (2012 : 64), menyatakan bahwa implementasi merupakan "administrative task of transferring policy commitments into practice". Implementasi merupakan cara atau bentuk pengubahan dari keputusan ke dalam aplikasi. Dengan demikian implementasi kebijakan merupakan upaya untuk melaksanakan apa yang telah diputuskan oleh pengambil kebijakan. Agar implementasi sebuah kebijakan publik dapat berjalan dengan baik, Baedhowi dalam Muhdi dan Sapto Budoyo, 2012 : 64-65), menyatakan diperlukan beberapa faktor penting, yaitu: (a) kebijakan publik itu sendiri yang mampu merespon isu dan masalah publik yang sedang berkembang, (b) pengambil keputusan yang mampu merumuskan kebijakan sesuai dengan aspirasi publik, (c) pelaksana kebijakan di lapangan yang mampu merealisasikan substansi kebijakan yang telah dirumuskan, (d) sasaran kebijakan publik yang mampu merespon dengan baik dan berpartisipasi aktif terhadap kebijakan yang dilaksanakan, (e) waktu pelaksanaan kebijakan yang memadai, serta (f) hasil hasil yang jelas yang ingin dicapai dalam pelaksanaan kebijakan tersebut.

Reley dan Frankilin dalam Winarno dalam Suntoro Irawan dan Hariri Hasan ( 2015 : 77) berpendapat bahwa implementasi adalah apa yang terjadi setelah peraturan perundang-undangan ditetapkan yang memberikan otoritas program, kebijakan, keuntungan atau suatu jenis keluaran yang nyata. Implementasi merujuk pada sejumlah kegiatan yang mengikuti pernyataan maksud tentang tujuan-tujuan program dan hasil-hasil yang diinginkan oleh para pejabat pemerintah. Implementasi mencakup tindakan-tindakan atau tanpa tindakan oleh berbagai aktor, khususnya para birokrat yang dimaksudkan untuk membuat program berjalan. Apabila pengertian implementasi ini dikaitkan dengan kebijakan publik, maka hal ini mempunyai makna sebagai aktivitas penyelesaian atau pelaksanaan suatu kebijakan yang telah ditetapkan dengan menggunakan sarana untuk mencapai tujuan. Dalam proses kebijakan publik implementasi kebijakan merupakan tahapan yang bersifat praktis dan dibedakan dari formulasi kebijakan yang dapat dipandang sebagai tahapan yang bersifat teoritis.

2. Model-Model Implementasi Kebijakan

a. Model Merilee S. Grindle

Keberhasilan menurut Grindle dalam Nugroho dalam Mulyadi Deddy (2015 : 6667) dipengaruhi oleh isi kebijakan dan lingkungan kebijakan. Ide dasarnya adalah bahwa setelah kebijakan ditranspormasikan, barulah implementasi kebijakan dilakukan. Keberhasilannya ditentukan oleh derajat implementability dari kebijakan tersebut.

Isi kebijakan tersebut mencakup hal-hal sebagai berikut :

1) Kepentingan yang terpengaruhi oleh kebijakan;

2) Jenis manfaat yang dihasilkan;

3) Derajat perubahan yang diinginkan;

4) Kedudukan pembuat kebijakan;

5) Siapa pelaksana program;

6) Sumber daya yang dikerahkan.

Sedangkan lingkungan kebijakan mencakup :

b. Model George C. Edward III 
BEduManageRs Journal

Borneo Educational Management and Research Journal, Vol.1, No.1, 2020

ISSN: 2747-0504

Edward III dalam Subroto dalam Mulyadi Eddy, (2015 : 68-69) mengemukakan bahwa ada 4 (empat) variabel yang mempengaruhi implementasi kebijakan, yaitu :

1). Komunikasi. Keberhasilan implementasi kebijakan mensyaratkan agar implementor mengetahui apa yang harus dilakukan. Apa yang menjadi tujuan dan sasaran kebijakan harus ditransmisikan kepada kelompok sasaran (target group) sehingga akan mengurangi distorsi implementasi. Apabila tujuan dan sasaran suatu kebijakan tidak jelas atau bahkan tidak diketahui sama sekali oleh kelompok sasaran, maka kemungkinan akan terjadi resistensi dari kelompok sasaran.

2) Sumberdaya. Walaupun isi kebijakan sudah dikomunikasikan secara jelas dan konsisten, tetapi apabila implementasi kekurangan sumber daya untuk melaksanakan, implementasi tidak akan berjalan efektif. Sumber daya tersebut dapat berbentuk sumber daya manusia, yaitu kompetensi implementor, dan sumber daya finansial. Sumber daya adalah faktor penting untuk implementasi kebijakan agar efektif. Tanpa sumber daya, kebijakan hanya tinggal di kertas menjadi dokumen saja.

3) Disposisi. Disposisi adalah watak dan karakteristik yang dimiliki oleh implementor, seperti komitmen, kejujuran, dan sifat demokratis. Apabila implementor memiliki disposisi yang baik, maka dia dapat menjalankan kebijakan dengan baik seperti apa yang diinginkan oleh pembuat kebijakan.

4) Struktur Birokrasi. Struktur organisasi yang bertugas mengimplemtasikan kebijakan mempunyai pengaruh yang signifikan terhadap implementasi kebijakan. Salah satu dari aspeks struktur yang penting dari setiap organisasi adalah adanya prosedur operasi yang standar (SOP). SOP menjadi pedoman bagi setiap implementor dalam bertindak. Struktur organisasi terlalu panjang akan cenderung melemahkan pengawasan dan menimbulkan prosedur birokrasi yang rumit dan kompleks.

c. Model Van Meter dan Van Horn

Van Meter dan Van Horn dalam Subarsono dalam Mulyadi Deddy, (2015 : 72 72) menjelaskan bahwa ada 6 variabel yang mempengaruhi kinerja implementasi, yaitu :
1) Standar dan sasaran kebijakan. Standar dan sasaran kebijakan harus jelas dan terukur, sehingga tidak menimbulkan interpretasi yang dapat menyebabkan terjadinya konflik diantara para agen implementasi.

2) Sumber daya. Kebijakan perlu didukung oleh sumber daya, baik itu sumber daya manusia maupun sumber daya non-manusia.

3) Komunikasi antar organisasi dan penguatan aktivitas. Dalam berbagai kasus, implementasi sebuah program terkadang perlu didukung dan dikoordinasikan dengan instansi lain agar tercapai keberhasilan yang diinginkan.

4) Karakteristik agen pelaksana. Sejauhmana kelompok-kelompok kepentingan memberikan dukungan bagi implentasi kebijakan. Termasuk di dalamnya karakteristik para partisipan yaitu mendukung atau menolak, kemudian juga bagaimana sifat opini publik yang ada di lingkungan dan apakah elite politik mendukung implementasi kebijakan.

5) Kondisi sosial, ekonomi dan politik. Kondisi sosial, ekonomi, dan politik mencakup sumber daya ekonomi lingkungan yang dapat mendukung implemnetasi kebijakan.

6) Disposisi implementor. Disposisi implementor mencakup 3 hal penting, yaitu :

(a) Respon implemntor terhadap kebijakan, yang akan mempengaruhi kemauannya untuk melaksanakan kebijakan.

(b) Koknisi, yaitu pemahamaannya terhadap kebijakan.

(c) Intensitas disposisi implementor yakni preferensi nilai yang dimiliki oleh implementor.

(d) Model Mazmanian dan Sabatier Mazmanian dan Sabatier dalam Subarsono dalam Mulyadi Deddy (2015 : 70) menjelaskan bahwa ada 3 kelompok variabel yang mempengaruhi keberhasilan implementasi

\section{HASIL PENELITIAN}

Kebijakan penerimaan peserta didik baru (PPDB) tahun pelajaran 2016/2017 yang dituangkan dalam Surat Keputusan Kepala Dinas Pendidikan dan Kebudayaan Kota Samarinda Nomor 421/757/DP.IIIA/101 Tentang Petunjuk Teknis Penerimaan Peserta Didik Baru (PPDB) Tahun Pelajaran 
BEduManageRs Journal

Borneo Educational Management and Research Journal, Vol.1, No.1, 2020

ISSN: 2747-0504

2016/2017, menurut pelaksana kebijakan

(Kepala Sekolah), dapat diimplementasikan pada jenjang pendidikan SMA, walaupun dengan berbagai permasalahan yang muncul, khususnya kebijakan yang berkaitan dengan prestasi, disabilitas/bina lingkungan/PTK, dan daya tampung, serta tahapan jalur pendaftaran. Pendapat pelaksana kebijakan (Kepala Sekolah) tersebut sejalan dengan pendapat yang diberikan sasaran kebijakan (masyarakat), yaitu mereka dapat menerima kebijakan tersebut, dengan catatan pada empat hal, yaitu masalah prestasi, disabilitas/bina lingkungan/PTK, pembatasan daya tampung, dan tahapan jalur penerimaan peserta didik baru (PPDB);

1. Berkaitan dengan kebijakan PPDB tahun 2016/2017 bagi calon peserta didik baru yang memiliki kebutuhan khusus, seperti disabilitas ada beberapa sekolah yang ditunjuk untuk mengakomodir calon peserta didik baru tersebut. Namun yang menjadi permasalahan adalah sekolah belum siap baik sarana/prasarana maupun tenaga guru yang mempunyai kompetensi di bidang kebutuhan khusus tersebut.

2. Berkaitan dengan tahapan pendaftaran jalur prestasi, disabilitas/bina lingkungan/PTK dilakukan sebelum jalur reguler/umum, menimbulkan banyak masalah. Oleh karena itu perlu dilakukan perbaikan, yaitu tahapan jalur pendaftaran prestasi, disabilitas/bina lingkungan/PTK dilakukan setelah tahapan jalur pendaftaran reguler/umum;

3. Sistem seleksi disabilitas/bina lingkungan/PTK berdasarkan jumlah nilai tertinggi hasil UN menimbulkan masalah. Untuk mengeliminir permasalahan yang muncul baik menurut pelaksana kebijakan maupun sasaran kebijakan perlu dilakukan seleksi berdasarkan radius domisili calon peserta didik. Kemudian tentang pembatasan wilayah calon peserta didik jalur disabilitas/bina lingkungan/PTK berasal dari satu kelurahan, juga perlu diubah dengan menghilangkan luasan wilayah asal calon peserta didik dan mengganti dengan radius domisili calon peserta didik;

4. Pembatasan daya tampung seperti tertuang dalam Surat Keputusan Kepala Dinas
Pendidikan dan Kebudayaan Kota Samarinda Nomor 421/757/DP.IIIA/101 Tentang Petunjuk Teknis Penerimaan Peserta Didik Baru (PPDB) Tahun Pelajaran 2016/2017, menurut pelaksana kebijakan (Kepala Sekolah) dan sasaran kebijakan (masyarakat) tidak dapat diimplementasikan ke semua sekolah atau diterima masyarakat, mengingat kondisi masing-masing sekolah berbeda.

\section{KESIMPULAN}

Berdasarkan temuan lapangan sehubungan dengan implementasi kebijakan penerimaan peserta didik baru tahun pelajaran 2016/2017 jenjang pendidikan SMA masih ada beberapa permasalahan seperti jalur prestasi, disabilitas/bina lingkungan/PTK, daya tampung, dan tahapan jalur pendaftaran, maka perlu dibuat rekomendasi kepada :

1. Pemerintah Kota Samarinda melalui Kepala Dinas Pendidikan dan Kebudayaan Kota Samarinda sebagai otoritas pembuat Kebijakan PPDB tahun 2016/2017 untuk melakukan evaluasi dan perbaikan kebijakan yang berkaitan dengan jalur prestasi, disabilitas/bina lingkungan/PTK, agar tahapan jalur pendaftaran dilakukan setelah tahapan jalur pendaftaran reguler/umum. Hal ini dimaksudkan agar calon peserta didik yang memiliki prestasi akademik kurang dapat memanfaatkan jalur tersebut;

2. Pemerintah Kota Samarinda melalui Kepala Dinas Pendidikan dan Kebudayaan Kota Samarinda sebagai otoritas pembuat Kebijakan PPDB tahun 2016/2017 untuk melakukan perbaikan kebijakan PPDB tahun 2016/2017 yang berkaitan dengan seleksi jalur bina lingkungan diubah dengan menggunakan radius domisili, demikian pula kebijakan PPDB tahun 2016/2017 yang berkaitan dengan tahapan jalur bina lingkungan dengan menggunakan batas wilayah domisili calon peserta didik dalam satu kelurahan untuk diperbaiki dengan menghilangkan batas wilayah domisili calon peserta didik dan cukup diganti dengan radius domisili;

3. Pemerintah Kota Samarinda melalui Kepala Dinas Pendidikan dan Kebudayaan Kota Samarinda sebagai otoritas pembuat 
BEduManageRs Journal

Borneo Educational Management and Research Journal, Vol.1, No.1, 2020

ISSN: 2747-0504

Kebijakan PPDB untuk melakukan perbaikan kebijakan PPDB tahun 2016/2017 yang berkaitan dengan pembatasan daya tampung, agar memenuhi infrastruktur yang mendukung kapasitas daya tampung sekolah, sehingga sekolah mampu menyediakan daya tampung sesuai dengan kondisi masyarakat.

4. Pemerintah Kota Samarinda melalui Kepala Dinas Pendidikan dan Kebudayaan Kota Samarinda sebagai otoritas pembuat kebijakan PPDB tahun pelajaran 2016/2017 untuk melibatkan masyarakat dalam proses penyusunan kebijakaan dan menganalisis situasi dan kondisi lapangan, agar implementasi kebijakan PPDB tahun pelajaran 2016/2017 dapat diterima masyarakat.

5. Bagi pelaksana kebijakan (Kepala Sekolah), agar melakukan evaluasi dan menyampaikan hasil evaluasinya kepada Kepala Dinas Pendidikan dan Kebudayaan Kota Samarinda sebagai bahan masukan untuk penyempurnaan kebijakan;

6. Bagi sasaran kebijakan (masyarakat), selalu melakukan pengawasan terhadap perbaikan kebijakan tersebut.

7. Dewan Pendidikan Kota Samarinda Peride 2015 - 2020 yang melakukan monitoring dalam proses implementasi kebijakan PPDB 2016/2017 merekomendasikan agar pemerintah (Disdikbud) perlu melakukan evaluasi terhadap implementasi kebijakan PPDB 2016/2017 dan melakukan penyempurnaan untuk pelaksanaan PPDB tahun berikutnya.

\section{DAFTAR PUSTAKA}

Abidin dalam Suntoro Irawan dan Hariri Hasan, 2015, Kebijakan Publik, Graha Ilmu, Yogyakarta.

Adisasmita Rahardjo, 2015, Analisis Kebijakan Publik, Graha Ilmu, Yogyakarta.

Anderson dalam Islamy dalam Suntoro Irawan dan Hariri Hasan, 2015, Kebijakan Publik, Graha Ilmu, Yogyakarta.

Baedhowi dalam Muhdi dan Sapto Budoyo, 2012, Implementasi Kebijakan Penerimaan Peserta Didik, Media Penelitian Pendidikan IKIP PGRI

Semarang Vol 6 No. 2 bulan Desember 2013.

Carl, G, and C. Fudge, 1981, dalam Islamy, 1984 dalam eprint.uns.ac.id/ 21921/3/D0111046 BAB2.PDF.

Mulyadi Deddy, 2015, Studi Kebijakan Publik dan Pelayanan Publik, Alfabeta, Bandung

Daniel Bell dalam Parsons Wayne, 2001, Public Policy, Pengantar Teori dan Pratik Analisis Kebijakan, Kencana Prenadamedia Group, Jakarta.

Deleon dalam Fischer, Miller, dan Sidney, Terjemahan Imam Baihaqie, 2015, Handdbook Analisis Kebijakan Publik, Teori, Politik dan Metode, Penerbit Nusa Media, PO Box 137 Ujungberung, Bandung.

Dye dalam Suntoro Irawan dan Hariri Hasan, 2015, Kebijakan Publik, Graha Ilmu, Yogyakarta.

Dye dalam Islamy dalam Suntoro Irawan dan Hariri Hasan, 2015, Kebijakan Publik, Graha Ilmu, Yogyakarta.

Dunn, William N, 2003, Pengantar Analisis Kebijakan Publik, Edisi kedua, PT Gajah Mada University Press, Yogyakarta.

Edward III, George. C. Dalam Subarsono dalam Mulyadi Deddy, 2015, StudiKebijakan Publik dan Pelayanan Publik, Alfabeta, Bandung.

Elmore, Sabatier, dan Goggin dalam Fischer, Miller, dan Sidney, Terjemahan Imam Baihaqie, 2015, Handdbook Analisis Kebijakan Publik, Teori, Politik dan Metode, Penerbit Nusa Media, PO Box 137 Ujungberung, Bandung.

Easton dalam Suntoro Irawan dan Hariri Hasan, 2015, Kebijakan Publik, Graha Ilmu, Yogyakarta.

Fischer, Miller, dan Sidney, 2015, Terjemahan Imam Baihaqie, 2015, Handdbook Analisis Kebijakan Publik, Teori, Politik dan Metode, Penerbit Nusa Media, PO Box 137 Ujungberung, Bandung.

Friederick, dalan Suntoro Irwanto dan Hariri Hasan, 2015, Kebijakan Publik, Graha Ilmu, Yogyakarta.

Grindle dalam Haedar, Akib; Antonius Tarigan dalam Mulyadi Deddy, 2015, Studi Kebijakan Publik dan Pelayanan Publik, Penerbit Alfabeta, Bandung. 
BEduManageRs Journal

Borneo Educational Management and Research Journal, Vol.1, No.1, 2020

ISSN: 2747-0504

Grindle, Meriles S. dalam Nugroho dalam Mulyadi Deddy, 2015, Studi Kebijakan Publik dan Pelayanan Publik, Penerbit Alfabeta, Bandung.

Gerston dalam Muhdi dan Sapto Budoyo, 2012, Implementasi Kebijakan Penerimaan Peserta Didik, Media Penelitian Pendidikan, IKIP PGRI Semarang Vol. 6 No. 2 bulan Desember 2013.

Gumilar, Studi Kasus Strategi Implementasi Kebijakan dan Manajemen Program Pendanaan Kompetisi-Indeks Pembangunan Manusia PPK-IPM, drgumilar.wordpress.com/...09/04/26/ab strak-desertasi

Gunawan, 2000, Sosiologi Pendidikan, PT Asdi Malasatya, Jakarta.

Imron Ali, 1993, "Masalah, Agenda, dan Formulasi Kebijakan Pendidikan" jurnal manajemen pendidikan volome 1 nomor 1 Jurusan Administrasi Pendidikan FIP IKIP Malang.

Islamy dalam Suntoro Irawan dan Hariri Hasan, 2015, Kebijakan Publik, Graha Ilmu, Yogyakarta.

Lasswell dalam Parsons Wayne, 2001, Public Policy, Kencana Prenadamedia Group, Jakarta.

Mazmanian dan Sabatier dalam Subarsono dalam Mulyadi Deddy, 2015, Studi Kebijakan Publik dan Pelayanan Publik, Penerbit Alfabeta, Bandung.

Miles dan Hubermen dalam Rahmad Sahid, 2011, Analisis Data Penelitian Kualitatif Model Miles dan Huberman, sangit26.blogspot.com/...a-penelitiankualitatif.html

Miliband dalam Parsons Wayne, 2001, Public Policy, Pengantar Teori dan Pratik Analisis Kebijakan, Kencana Prenadamedia Group, Jakarta.

Mazmanian dan Sabatier dalam Fischer, Miller, dan Sidney, 2015, Terjemahan Imam Baihaqie, 2015, Handdbook Analisis Kebijakan Publik, Teori, Politik dan Metode, Penerbit Nusa Media, PO Box 137 Ujungberung, Bandung.

Muhdi dan Sapto Budoyo, 2012, Implementasi Kebijakan Penerimaan Peserta Didik, e-jurnal.upgrismg. ac.id/...iapenelitianpendidikan/...

Mulyadi Deddy, 2015, Studi Kebijakan Publik dan Pelayanan Publik, Penerbit Alfabeta, Bandung.

Nasution (1992), Metodologi Penelitian NaturalistikKualitatif, Tarsito, Bandung,

Nasution, dalam Wahyudin (2010), Kebijakan Bantuan Operasional dan Implementasinya dalam Peningkatan Mutu Pendidikan, Program Pascasarjana, Universitas Islam Nusantara, Bandung.

Parsons Wayne, 2001, Public Policy, Pengantar Teori dan Pratik Analisis Kebijakan, Kencana Prenadamedia Group, Jakarta

Purwanto EA dan Sulistyastuti DR, 2015, Implementasi Kebijakan Publik, Penerbit Gava Media, Yogyakarta.

Peters dalam Sallis, 2010, (alih bahasa oleh Ahmad Ali Riyadi, dkk), Manajemen Mutu Terpadu Pendidikan, Sampangan Gg. Perkutut No. 325-B Jalan Wonosari, Baturetno Banguntapan, Yogyakarta.

Raksasataya Amara dalam Islamy dalam Suntoro Irawan dan Hariri Hasan 2015, Kebijakan Publik, Graha Ilmu, Yogyakarta.

Sabatier dan Mazmanian, dalam Stillman dan Hill, dalam Mulyadi Deddy, 2015, Studi Kebijakan Publik dan Pelayanan Publik, Alfabeta, Bandung.

R.E. Allen, 1990, The Concise Oxford Dictionary of Current English-8th ed, Clarendon Press Oxford.

Sallis Edward, 2010, (alih bahasa oleh Ahmad Ali Riyadi, dkk), Manajemen Mutu Terpadu Pendidikan, Sampangan Gg. Perkutut No. 325-B Jalan Wonosari, Baturetno Banguntapan, Yogyakarta.

Sanusi Achmad, 2009, Spiral Dynamics, Nusantara Education Review, Program Pascasarjana Universitas Islam Nusantara.

Smith dalam Parsons Wayne, 2001, Public Policy, Pengantar Teori dan Pratik Analisis Kebijakan, Kencana Prenadamedia Group, Jakarta.

Sudjana, 1999, Manajemen Program Pendidikan, Falah Production.

Suntoro Irawan dan Hariri Hasan, 2015, Kebijakan Publik, Graha Ilmu, Yogyakarta.

ata Sumadi (1987), Pengembangan Tes Hasil Belajar, Rajawali Pers, Jakarta. 
BEduManageRs Journal

Borneo Educational Management and Research Journal, Vol.1, No.1, 2020

ISSN: 2747-0504

Thoha dalam Suntoro Irawan dan Hariri Hasan, 2015, Kebijakan Publik, Graha Ilmu, Yogyakarta

Tilaar, 2002, Perubahan Sosial dan Pendidikan, PT gramedia Widiasarana, Jakarta.

Terry GR dalam Mulyadi Deddy, 2015, Studi Kebijakan Publik dan Pelayanan Publik, Penerbit Alfabeta, Bandung.

Van Meter dan Van Horn, dalam Subarsono dalam Mulyadi Deddy, 2015, Studi Kebijakan Publik dan Pelayanan Publik, Penerbit Alfabeta, Bandung.

Van meter dan Van Horn dalam Wibawa, dkk dalam Mulyadi Deddy, 2015, Studi Kebijakan Publik dan Pelayanan Publik, Penerbit Alfabeta, Bandung.

Wadsworth et.al yang dikutuip oleh Adviso

Dynamics, Nusantara Education Review, Program Pascasarjana Universitas Islam Nusantara.

Wibawa dalam Akib Haedar, dosen Program Sarjana dan Pascasarjana Universitas Negeri Makassar, STIA-LAN dan UNISMUH Makassar dan Tarigan Antonius, Kasubdit Kerjasama Kelembagaan Bappenas Jakarta, www.scrbd.com/doc/50865843.

Wayne Parsons, 2001, Public Policy, Kencana Prenadamedia Group, Jakarta.

Wilson, dalam Wayne Parsons, 2001, Public Policy Pengantar Teori dan Praktik Analisis Kebijakan, Kencana Prenadamedia Group, Jakarta. 